\title{
Effect of fuzzy PID controller on feedback control systems based on wireless sensor network
}

\author{
Anas A. Hussien ${ }^{1}$, Mehdi J. Marie ${ }^{2}$, Khalaf S. Gaeid ${ }^{3}$ \\ ${ }^{1}$ Department of Computer Engineering, Al-Nahrain University, Iraq \\ ${ }^{2}$ Ministry of Industry and Minerals, Iraq \\ ${ }^{3}$ Department of Electrical Engineering, Tikrit University, Iraq
}

\begin{tabular}{l} 
Article Info \\
\hline Article history: \\
Received Jun 29, 2019 \\
Revised Nov 16, 2019 \\
Accepted Nov 26, 2019 \\
\hline
\end{tabular}

\section{Keywords:}

Delay time

Fuzzy logic

PID controller

Stability

WFCS

\begin{abstract}
Wireless Networked control system (WNCS) has an important in all aspects of the life and in the research fields of Engineering. In this article, a real-time implementation of the wireless feedback control system (WFCS) is performed. The stability issue in the closed-loop control system still suffer from noise, disturbances, and need careful considerations to handle it. Three cases to discover the ability of a Fuzzy PID controller to maintain better angular position control system (PCS) is addressed and controlled by a personal computer through a wireless sensor network(WSN) constructed by ZigBee platforms. The practical issues related with the design and implementation of the wireless computerized control system (WCCS) is discussed and analyzed. The simulation results carried out with Matlab/ Simulink 2018b. Different parameters effect such as maximum overshoot, sampling frequency, distance and delay time have been studied. These effects on overall system performance would be discussed. Improving the efficient use of ZigBee platform for WFCS. The simulation and experimental results prove the proposed algorithm in the field of wireless control system.
\end{abstract}

Copyright $(2020$ Institute of Advanced Engineering and Science. All rights reserved.

Corresponding Author:

Anas A. Hussien,

Department of Computer Engineering,

Al-Nahrain University,

Al Jadriyah, Baghdad, Iraq.

Email: anasali78@yahoo.com

\section{INTRODUCTION}

Wireless networked control system (WNCS) has a vital role in many aspects of engineering since the late 1990s. The advantages of WNCS such as fewer cables, easy to developed, maintain and resource sharing, according to nodes ability in the NCS is connected to network directly. Great advances in control engineering, communication, smart communications telecommunications, and for all digital services [1, 2]. This leads to more sophisticated performance in the life. The system performance depends on the capabilities of the sensors, switches, relays, and actuators. Smart systems has been developed to yield efficient tools in wireless feedback control systems (WFCSs) such diagnosis, identification monitoring used for performance evaluation. Hence the whole life will be enhanced. Another important issue leads to more efficient WCS is the intersection of system engineering (control and communication), management and application domain expertise as can shown in Figure 1.

Feedback control systems (FCS) is the control loops in which the feedback system are closed through a real-time network and called networked control systems (NCS) which is used to reduce both cost of the device and its weight [3]. Since the WNCS deal with the real-time control system it's combined with cyber-physical system (CPS) and Tactile Internet (TI) [4]. The objective of any FCS is to ensure that the FCS has desirable output response with high accuracy, ability to handle the attenuation, high speed and zero steady-state response as well [5]. 


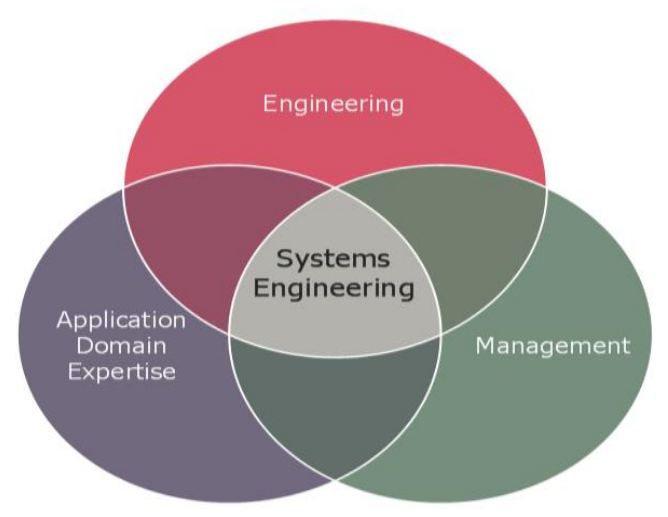

Figure 1. Systems engineering improvement [6]

For the WNCS systems the developed performance specifications will ensure high connectivity between the devices at same time, the reliability will be increased to reach better control and monitoring during the operation period [7]. In the WNCS it's difficult to send a signal to a single receiver or to avoid receiving signals from the transmitters that have a power in the working region [8] and its consists of sensor nodes in the network for collecting, processing, storing and transferring information [9]. FLC and PID structure for H5 inverter topologies describing are observed in terms of settling time, stability, and harmonic distortions presented in [10]. Takagi-Sugeno (T-S) fuzzy model with PID controller for stochastic stabilization problem of uncertain WN control in the random network induced delays presented in [11]. Fuzzy Logic control in the field of Telecommunications at both the network and physical layers, is presented [12]. Hence, the control is a central circuit for wireless control systems as can be shown in Figure 2:

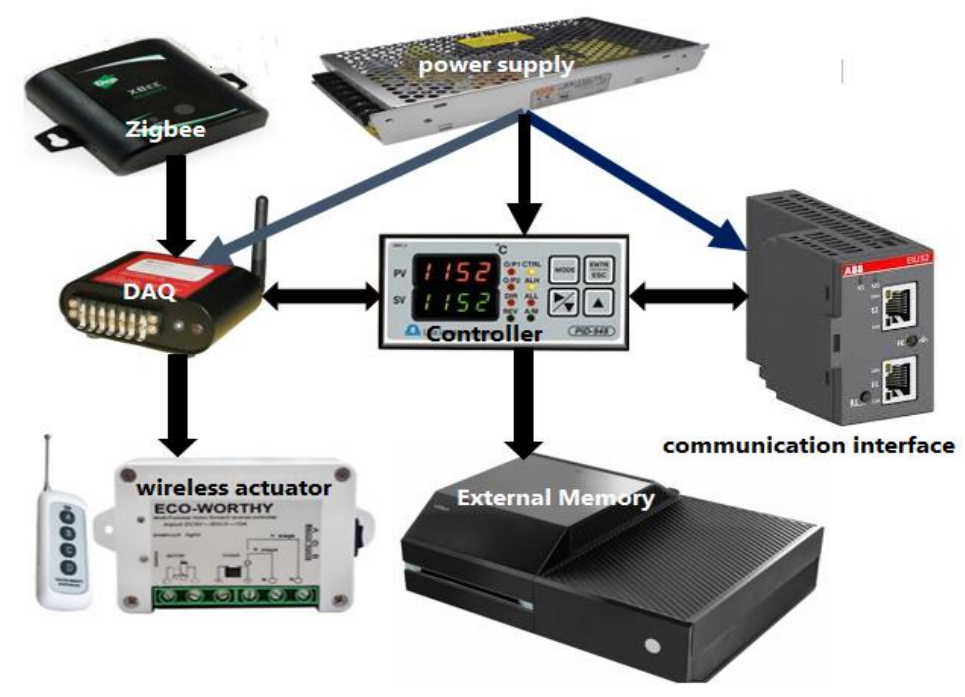

Figure 2. Hardware implemintation of the proposed work

Wireless sensor networks (WSNs), can be used in many application fields, such as security and military, industry 4.0 architecture and the environment. The data connectivity between data delivery source and the consumed energy circuits with high efficiency is the key factor in the network specifications [13, 14]. WFCSs research area is classified into Control of the network, Control over the network and Multi-agent systems $[15,16]$. The new devices system have to be a multi-layered, machine-(to-user, to-machine, to cloud) server capability and a vast number of smart nodes have been introduced into WFCS system [17]. In the literature, there are a lot of works have been done in the WFCSs in the last two decades to solve the problems in this field. 
The WSN implementation based on ZigBee technology to monitor the history and current temperature information is carried out by [18]. Robust proportional integral derivative (PID) Controllers for time delay systems in WN for various uncertainties as a feedback method for controlling a plant with sensors and actuators used. Communication delay occur due to a various parts of system [19]. WNCS with induced delays and with modified packet compared to the conventional system to reduce number of transmissions is presented in [20].

Investigation of the transmission of WCSs with relay of limited power resources system with discrete-time is introduced into the algorithm for better efficiency in control and transmission [21]. The influence of packet loss on WFCS is important to design controllers to reduce the disturbance between transmissions and the received information. The results proves that, the power spectrum density (PSD) of the effect on the controller is not constant [22]. A proportional-integral-derivative (PID) controller for controlling a set of wireless devices to form a WFCS that can affect the orientation of the system to desired state is presented in [23]. Stability of WCS under Denial of Service (DoS) attacks has been investigated to the modern concept of system stability during cyber-attack [24]. A cross-layer design for control and communication layers for WFCS is analyzed, and an optimized receiver design for state feedback is presented in [25]. The rest of this article is arranged as: in section II, the materials and methods is presented. In section III, results and discussion is given. The article is concluded in section IV.

\section{MATERIALS AND METHODS}

The FCS communication and control algorithm designed through prototype test bed consisting of a plant position control system (PCS). The plant type is very important in the actuators selection for the position control of the systems [26]. Required torque response to the DC motor shaft, the actuator control signal can change the system position precisely. Hence, fast and accurate torque control is obtained which are the major objectives for the FWPCS [27].

Two kinds of torque control schemes are presented in the literatures either current or speed mode. The current mode is realized and used due to its simplicity features [28, 29]. The FW motor is DC. Its inductance is very small and can be negligible. This FWCS is sensitive to any torque disturbances in the current control scheme. To enhance steady state response, the speed control scheme is used to improve accuracy and reduce the effect of the disturbances. Most of the applications uses the speed control scheme. The current scheme controller transfer function will be as in (1):

$$
\frac{T_{o}(s)}{\tau_{L}(s)}=\frac{\tau_{i}}{\tau_{i} s+1}
$$

The output torque response of the flywheel fellow the reference toque precisely when the value of $\tau_{i} \gg>1$. The transfer function of speed scheme, from output torque (To) to flywheel torque $(\tau \mathrm{L})$ will be as in (2).

$$
\frac{T_{o}(s)}{\tau_{L}(s)}=\frac{\tau_{\omega}}{\tau_{\omega} s+1}
$$

The output torque response of the flywheel fellow the reference toque precisely when the value of $\tau_{\omega}<<1$. The FLC implemented by the following steps:

- 1. Modify the real value into fuzzy values (Fuzzification)

- 2. Set of rules in this process (Knowledge base),

- 3. Reasons application to compute the fuzzy output (Inference engine)

- 4. Changing the fuzzy values into real and single values (Defuzzification)

In the FLC, there are two fuzzy inference system (FIS)"

- 1. Sugeno which is obtain the output response according to its input

- 2. Mamdani which is obtain the response of the process according to the membership function (MF) are the main.

The error e $(\mathrm{k})$ is difference between the input and output response and the change of the output (y (k)-y (k-1)) are used as input signals to the FIS. The fuzzy PID controller is linear as can be shown in Figure 3. 


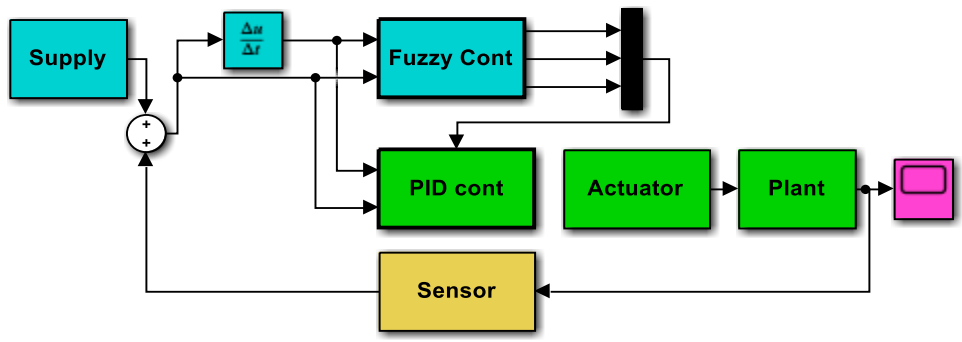

Figure 3. Fuzzy PID network control system

According to Figure 3, the combination of the FL rule tables of $K_{p}, K_{i}, K_{d}$, the fuzzy FC model and the modified PID parameters gain will be as in (3) :

$$
\begin{aligned}
& \dot{K}_{p}=K_{p}+[\text { error, rateof error }]_{p} \\
& \dot{K}_{i}=K_{i}+[\text { error, rateof error }]_{i} \\
& \dot{K}_{d}=K_{d}+[\text { error, rateof error }]_{d}
\end{aligned}
$$

The fuzzy truth table used in this paper as in the Table 1:

Table 1. Fuzzy truth table

\begin{tabular}{lccrc}
\hline & \multicolumn{4}{c}{$\operatorname{Error}(\mathrm{E})$} \\
\hline \multirow{3}{*}{ Rate of Error $(\Delta \mathrm{E})$} & $\mathrm{NL}$ & $\mathrm{N}$ & $\mathrm{Z}$ & $\mathrm{P}$ \\
& $\mathrm{N}$ & $\mathrm{NH}$ & $\mathrm{NL}$ & $\mathrm{Z}$ \\
& $\mathrm{Z}$ & $\mathrm{NL}$ & $\mathrm{Z}$ & $\mathrm{PL}$ \\
& $\mathrm{P}$ & $\mathrm{Z}$ & $\mathrm{PL}$ & $\mathrm{PH}$ \\
\hline
\end{tabular}

where N, NL, Z, P, PL, PH is refers to negative, negative low, zero, positive, positive low and positive high respectively.

The implementation of the control server of WFCS illustrated in Figure 2. The National instrument (NI) equipment's has been used in this model as analogue output monitoring. The NI data acquisition system Dev3-6008 is used as well. Serial transmitter and receiver to send the required information with data conversion from the int13 and doubled conversion to synchronize the information to ensure better matching between any two circuits. The position control system is used with wireless controllers to measure the angle of permanent-magnet DC motor. In the plant side, four wireless sensors and two wireless nodes have implemented on a single-hop wireless network and another two wireless nodes at the controller side used as well [30].

\section{RESULTS AND ANALYSIS}

The performance specifications such as time delay which is the time needed to reach half of the output response, bandwidth and noises effect on the stability and of the WFCS. "It is well known that a continuous time LTI system is BIBO stable if and only if the impulse response is absolutely integrable. Equivalently, the necessary and sufficient condition for continuous time LTI system to be BIBO stable is that all the poles of rational transfer function lie in the left half the s-plane (i.e. to the left of jw axis)" [31]. Rise time (tr) which is the time needed to reach $100 \%$ of the output response and its inversely proportional to the bandwidth, maximum overshoot (Mp), steady state error (ESS) and settling time (ts) can be used to check the stability of the system. Figure 4 illustrates the system implementation using Matlab2018b/Simulink [32]. 


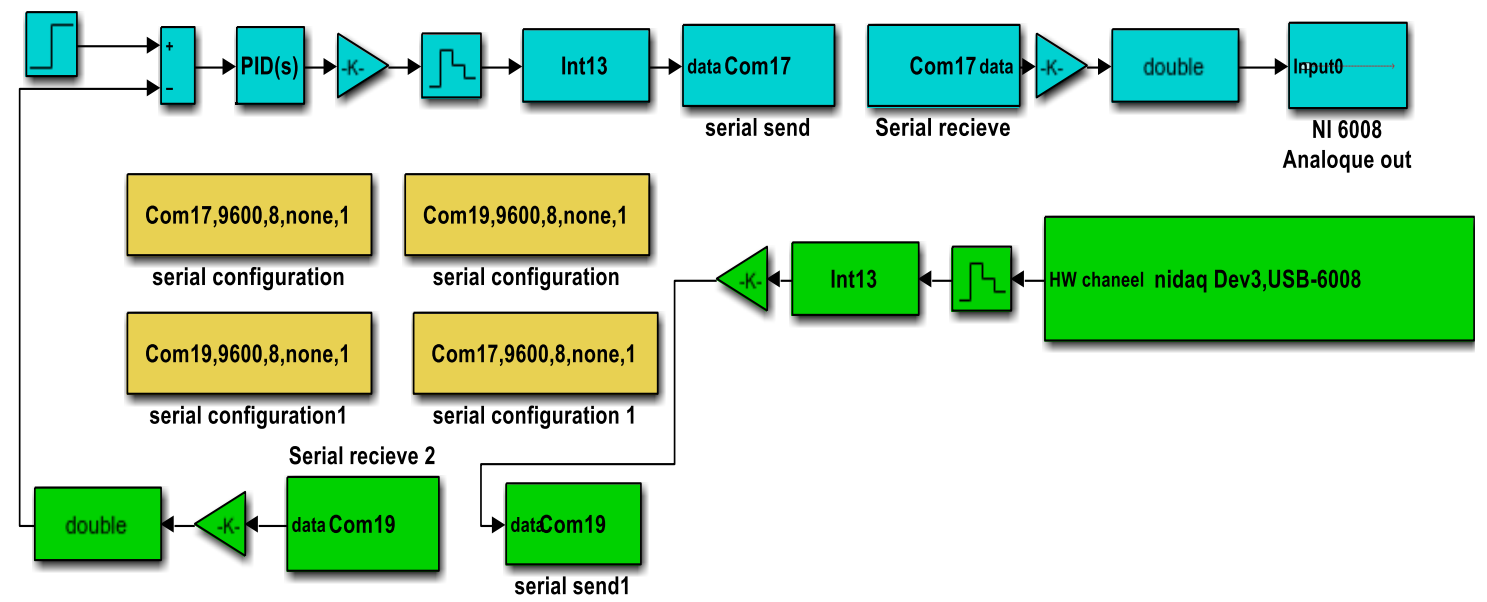

Figure 4. Implementation of WFCS using simulink

$2^{\text {nd }}$ order control system inertial plant has been investigated in this work with the transfer function as in (4)

$$
G_{\text {plant }}(s)=\frac{1.4}{s^{2}+8 s+16}
$$

The controller is the central unit of the WFCS as mentioned earlier and its can be found in the controller (client) side to drive the DC motor to the required angular position. PID controller is used to make the output fellow directly the reference input. The mathematical model of parallel PID controller [33] as in (5)

$$
G(s)=\frac{K_{d} s^{2}+K_{p} s+K_{i}}{s}
$$

where $K_{\mathrm{p}}, K_{\mathrm{i}}, K_{\mathrm{d}}$ refers to the proportional gain, the integral gain and the differential gain, respectively. The P-controller where $K_{\mathrm{p}}=0.042$, ( $\mathrm{Ki}$ and $\mathrm{Kd}$ are equal to zero. This mean the PID transfer function will be as in (6)

$$
G=0.042
$$

The output response of the WFCS system is shown in Figure 5. Figure 6 shows the error signal which is control signal to the controller. Figure 7 shows the controller efforts of PID controller and FPID controller. The high level effort related to the PID controller and lower control level due to FPID controller.

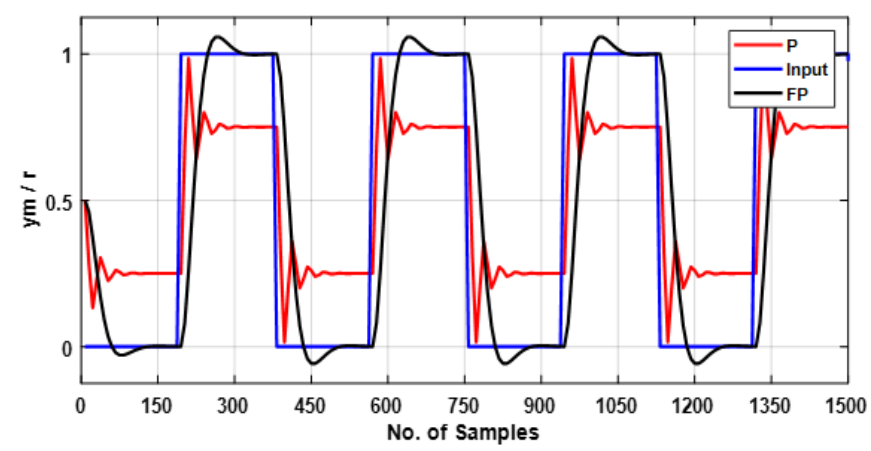

Figure 5. System response with P-controller 

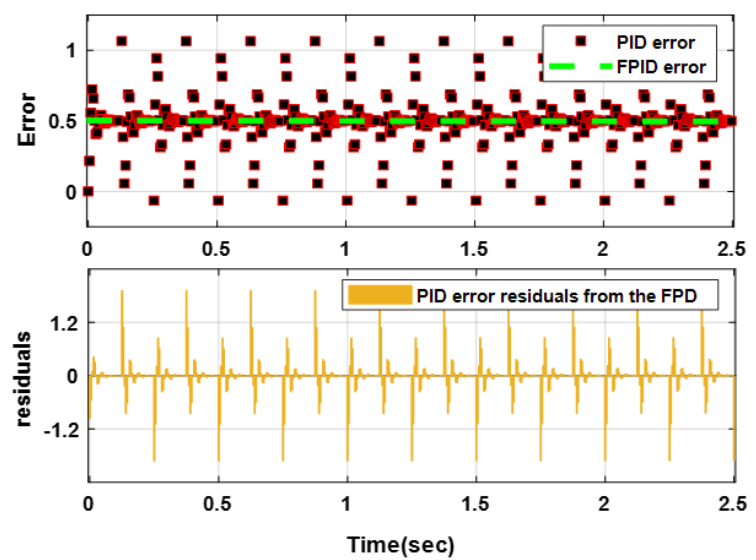

Figure 6. Error (control) signal and residuals between FPD and PID

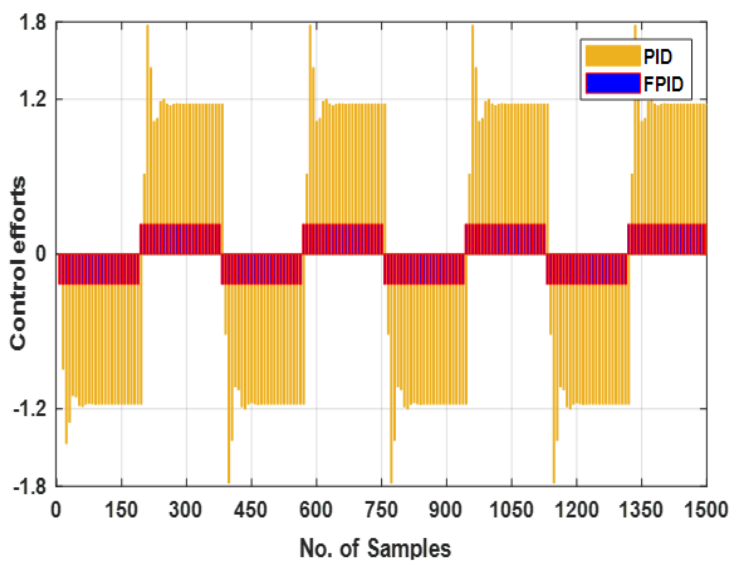

Figure 7. Controller efforts

The PI-controller is used with $\left(K_{\mathrm{p}}=0.05, K_{\mathrm{i}}=0.02\right.$ and $\left.K_{\mathrm{d}}=0\right)$. The PID transfer function in this case will be as in (7).

$$
G(s)=\frac{0.05 s+0.02}{s}
$$

The output response is shown in Figure 8. It is clear that the SSE is reduced and the output fellow the reference input but with some repeating overshoot in the transient region. The PID controller is used to enhance the overall response of the system, PID parameters are tuned according to the Ziegler-Nichols and particular swarm optimization methods. Figure 9 shows the system response with $K_{\mathrm{p}}=0.06, K_{\mathrm{i}}=0.035$ and $K_{d}=0.03$.

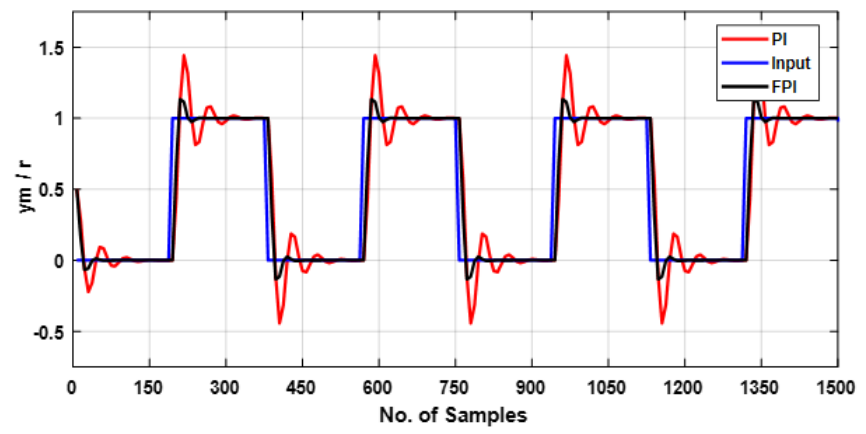

Figure 8. System response with PI-controller

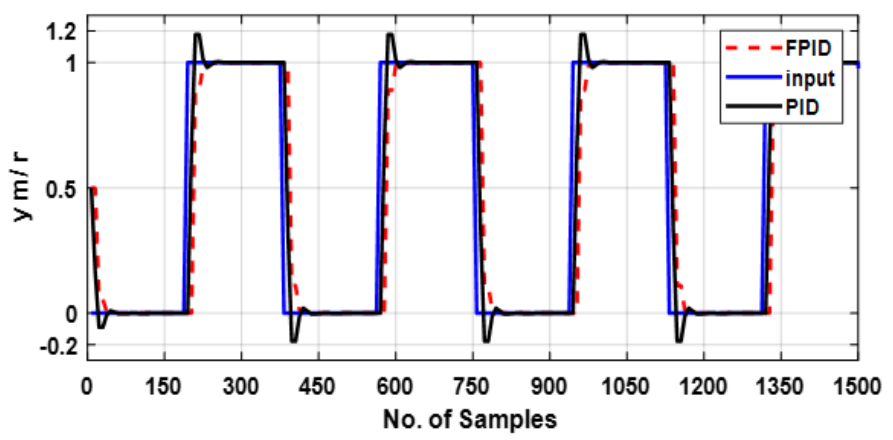

Figure 9. System response with PID-controller 
The transfer function of PID controller in this case as in (8).

$$
G(s)=\frac{0.03 s^{2}+0.06 s+0.035}{s}
$$

The simulations results for final two case studies are summarized in graphical user interface (GUI) 1 , as shown in Figure 10. Last case study performed by changing the distance between client and server suddenly to check the output response. The response of the WFCS is illustrated in the Figure 11.

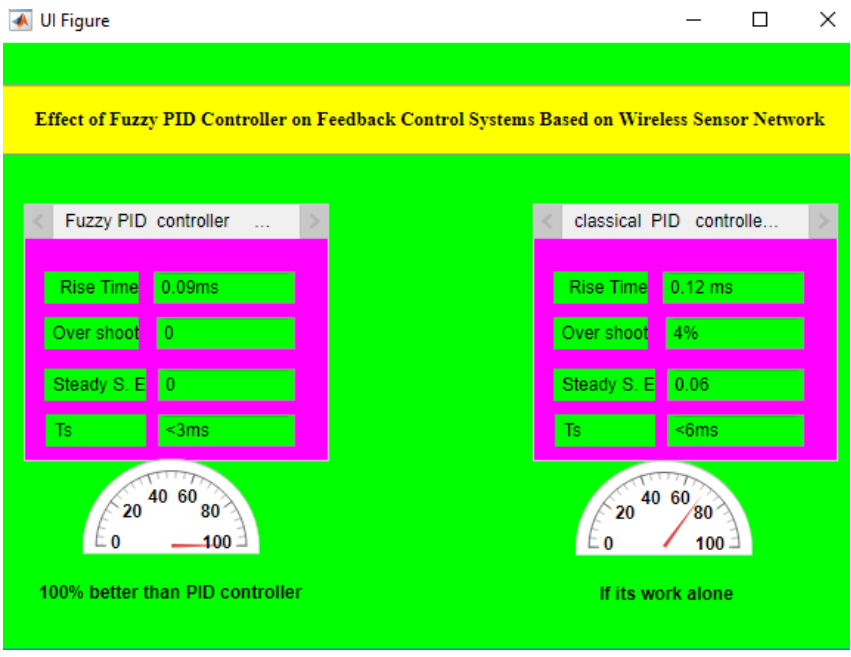

Figure 10. Performance specifications of the both controllers

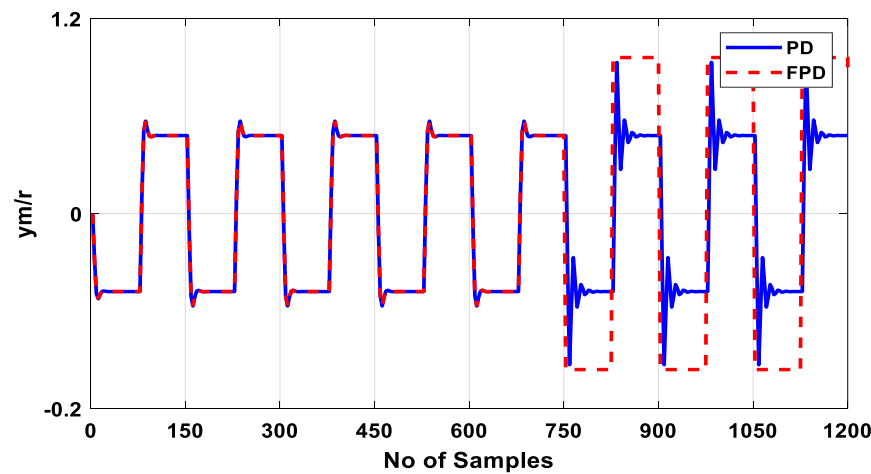

Figure 11. Variable distance output response with PD controller

It had been noticed that after the instant $\mathrm{k}=1700$ which corresponds to reaching to $15 \mathrm{~m}$, the output response perturbation with an overshoot occur after this instant with $0.4 \mathrm{msec}$ sampling time. Periodogram of the Welch power spectral density (PSD) calculated as a physical frequency function for given sampling frequency (fs). To evaluate the performance of Welch method [34], the following expression is used to estimate the performance of Welch method as in (9)

$$
P_{w}\left(e^{j w}\right)=\frac{1}{k} \sum_{i=0}^{k-1} P_{m}(i)\left(e^{j w}\right)
$$

where

$K$ is the sequence of covered data points

$P_{\mathrm{m}}$ mean of the performance 


$$
w=\frac{2 \pi f}{f_{s}}
$$

$f$ is the tonal frequency

The position of the maximum power results in the desired frequency.

Figure 12 shows the periodogram response for the output response during the operation for the WFCS with classical PID controller and fuzzy PID controller (FPID). Its quit evidence to the stability of the system due to oscillation frequency or decay appeared in the output response for the system with classical PID controller and stable in the FPID controller system. The delay time (Td) is another important factor to be investigated. The Td between client and server is checked according to the facilities of delay block putted in different locations. Figure 13 shows the output response when the path between sensor and controller is changed with Simulink delay block. It is obvious that, the stability is decreased and an overshoot is occur and the overall performance is degraded. Finally the validation of $96.1 \%$ between the transmitting and receiving information data of the WFCS for PID and $100 \%$ for the fuzzy PID controller (FPID) which ensure better stability as can be shown in Figure 14.

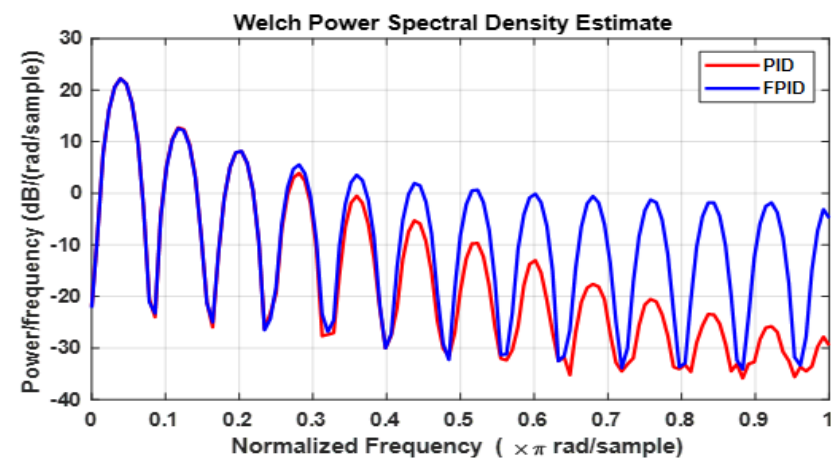

Figure 12. Power spectral density

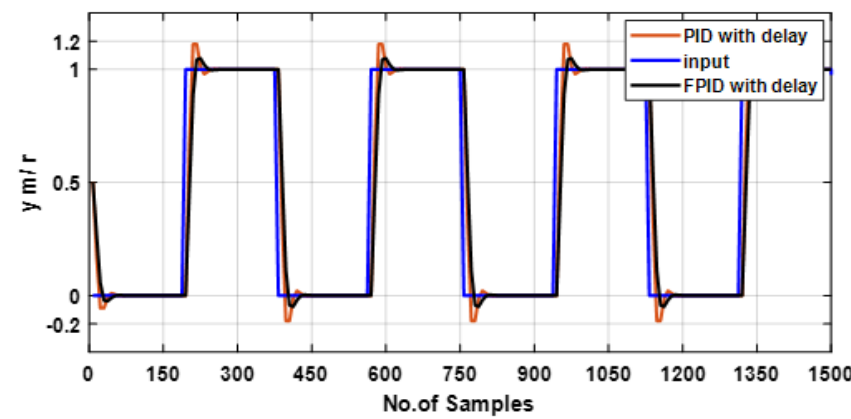

Figure 13. PID controller system response with time delay

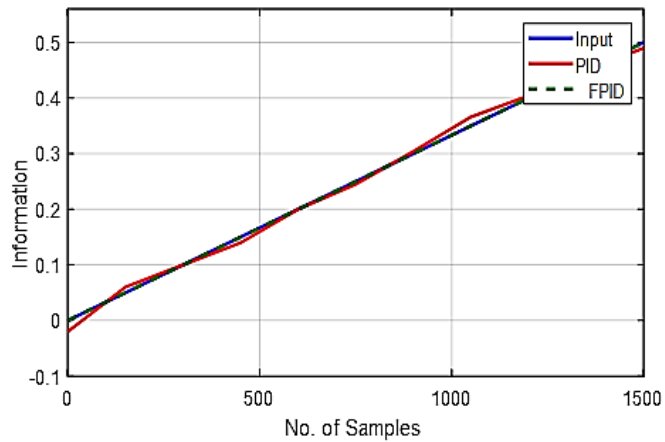

Figure 14. Transmitting and receiving information 


\section{CONCLUSION}

WFCS plays important role and considered it as fundamental technology in control systems applications. In this manuscript a prototype is implemented practically to investigate the main important related to the stability and main lack parameters effects on the feasibility for applting WFCSs. The plant control through FPID controller is best solution to ensure the stability compared to the classical PID controller. Time delay between the client and server is effects the stability. The sufficient selection of the Kp, $\mathrm{Ki}$ and $\mathrm{Kd}$ is pay vital role in the maintain the good performance specification of the WFCS. The estimated PSD maintain the energy of the signal independently of the data type and length. The effect of noise and distance and direction between the client and the server have been addressed and studied. Data collection strategies from the plant using Matlab/Simulink blocks is proposed and implemented. High accuracy and fast speed reaction between the transmitter and receiver in obtained. Finally, the most important literatures in the field WFCS is highlighted.

\section{REFERENCES}

[1] M. J. Marie, G. A. Al-Suhail and S. Al-Majeed, "Client-server based wireless networked control system," 2016 IEEE East-West Design \& Test Symposium (EWDTS), Yerevan, pp. 1-7, 2016.

[2] G. Samara and M. Aljaidi, "Efficient energy, cost reduction, and QoS based routing protocol for wireless sensor networks," International Journal of Electrical and Computer Engineering (IJECE), vol. 9, no. 1, pp. 496-504, 2019.

[3] V. Lopez and C.T. Abdallah, "Recent Advances on Linear Control Theory under Communication Constraints: A Survey," Diterranean Conference on Control and Automation, Italy, 2006.

[4] P. Park, S. Coleri Ergen, C. Fischione, C. Lu and K. H. Johansson, "Wireless Network Design for Control Systems: A Survey," in IEEE Communications Surveys \& Tutorials, Second quarter, vol. 20, no. 2, pp. 978-1013 2018.

[5] K. J. Astrom and B.Wittenmark, Computer-Controlled Systems: Theory and Design, Prentice-Hall, 1997.

[6] [Online], Available: https://www.conceptdraw.com/examples/application-of-venn-diagram-in-engineering, 2019.

[7] Product Catalogue, "Innovative applications for wireless control and tele-metry," 2013. [Online], Available: www.remotecontroltech.com.

[8] L. Peterson and B. Davie, Computer Networks: A Systems Approach, 3rd Ed, the Morgan Kaufmann Series in Networking, 2012.

[9] A. Ali Hussien, M. Jameel Eidan, "Automatic ZigBee-Based Wireless Sensor Network for Real Time Temperature Control," International Journal of Wireless Communications and Networking Technologies, vol. 4, no. 4, pp. 63-68, 2015.

[10] M. Ali Khanm, "Voltage-Balancing Control for Stand-Alone $\mathrm{H}_{5}$ Transformerless Inverters. Applications of Computing, Automation and Wireless Systems in Electrical Engineering," Springer, pp. 663-675, 2019.

[11] X. Lv, Juntao F., Y Sun, "Fuzzy PID Controller Design for Uncertain Networked Control Systems Based on T-S Fuzzy Model with Random Delays," International Journal of Fuzzy Systems, vol. 21, no. 2, pp. 571-582, 2019.

[12] E. Maria, "Applications of Soft Computing Techniques for Wireless Communications," Thesis in Blekinge Institute of Technology, Faculty of Engineering, Department of Applied Signal Processing, Karlskrona, 2019.

[13] H. Tandel, R. Shah, "A Survey Paper on Wireless Sensor Network," International Journal for Scientific Research \& Development, vol. 5, no. 10, pp. 907-909, 2017.

[14] Y. Zhou, et al, "Novel Energy-Efficient Data Gathering Scheme Exploiting Spatial-Temporal Correlation for Wireless Sensor Networks," Wireless Communications and Mobile Computing, vol. 2019, pp. 1-10, 2019.

[15] S. Zampieri, "Trends in networked control systems," in Proceedings of the 17th world congress. The international Fedration of Automatic Control, Korea, 2008.

[16] A. Ali Hussien, S. Ihsan Matloob, "The Comparative Study Some of Reactive and Proactive Routing Protocols in The Wireless Sensor Network," Journal of University of Babylon, Engineering Sciences, vol. 26, no. 4, pp. 195-207, 2018.

[17] X. Li, et al., "Efficient Deployment of Key Nodes for Optimal Coverage of Industrial Mobile Wireless Networks," Sensors, vol. 18, no. 2, pp. 1-16, 2018.

[18] A. Ali Hussien, A. Hameed Tawfeeq, "ZigBee-Based Wireless Sensor Network for Temperature Monitoring," International Journal of Computers \& Technology, vol. 10, no. 10, pp. 2062-2070, 2013.

[19] D. Sagar Sahu, S. Sharma, "Robust PID Controllers for Time Delay Systems in Wireless Network Environment," International Research Journal of Engineering and Technology, vol. 2, no. 03, pp. 727-730, 2015.

[20] Á. Cuenca, D. J. Antunes, A. Castillo, P. García, B. A. Khashooei and W. P. M. H. Heemels, "Periodic EventTriggered Sampling and Dual-Rate Control for a Wireless Networked Control System With Applications to UAVs," in IEEE Transactions on Industrial Electronics, vol. 66, no. 4, pp. 3157-3166, Apr. 2019.

[21] Y. Li, et al, "Sensor scheduling for relay-assisted wireless control systems with limited power," ISA Transactions, vol. 88, pp. 246-257, 2019.

[22] T. Ogura, et al, "Influence of packet loss on wireless feedback control systems as a disturbance," IEICE Communications Express. in press, 2019.

[23] He. Ross, et al, Devices and method of wireless attitude measurement and control of ground vehicle orientation, Publication of US20190079508A1 patent, 2019. 
[24] T. Ricky, Treloar, "A Physical Approach to Determining whether DoS Attacks Jeopardise the Nyquist Stability Criterion of Wireless Control Systems," ADFA Journal of Undergraduate Engineering, vol. 9, no. 1, pp. 1-10, 2016.

[25] K. Kobayashi, H. Okada and M. Katayama, "A Cross-Layer Optimized Receiver Design for Wireless Feedback Control Systems," in IEEE Transactions on Communications, vol. 66, no. 1, pp. 320-329, Jan. 2018.

[26] J. Fang, et al, "Precise accelerated torque control for small inductance brushless DC motor," IEEE Transactions on Power Electronics, vol. 28, no. 3, pp. 1400-1412, 2013.

[27] X. Zhou, et al, "High-Accuracy and Fast-Response Flywheel Torque Control," Mathematical Problems in Engineering, vol. 014, pp. 1-10, 2014.

[28] R. Varatharajoo and S. Fasoulas, "The combined energy and attitude control system for small satellites - earth observation missions," Acta Astronautica, vol. 56, no. 1-2, pp. 251-259, 2005.

[29] Q. Hu, "Sliding mode attitude control with L2-gain performance and vibration reduction of flexible spacecraft with actuator dynamics," Acta Astronautica, vol. 67, no. 5-6, pp. 572-583, 2010.

[30] C. Prabha, et al, "Wireless Multi-hop Ad-hoc Networks: A Review," IOSR Journal of Computer Engineering (IOSR-JCE), vol. 16, no. 2, pp. 54-62, 2014.

[31] R. Murthy, M. Jetta, "Test for Uniform bounded input, bounded output stability," EasyChair Preprint, 2019.

[32] [Online], Available: https://www.mathworks.com/2018.

[33] Y. Zhou, et al, "Optimization of PID Controller Based on Water Wave Optimization for an Automatic Voltage Regulator System," Journal of Information Technology and Control, vol. 48, no. 1, pp. 160-171, 2019.

[34] K.Brahmani, et al, "Estimation of Power Spectral Density of Seismic Data Using Welch Method," International Journal of Pure and Applied Mathematics, vol. 114, no. 10, pp. 211-219, 2017.

\section{BIOGRAPHIES OF AUTHORS}

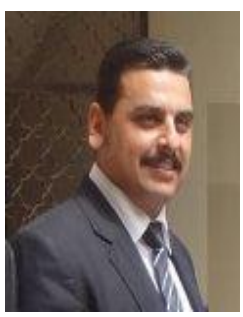

Anas Ali Hussien received the B.Sc. in Electronics and Communications Engineering in 1999, M.Sc. in Electronics and Communications Engineering / Electronic Circuits and Systems in 2001 and Ph.D. in Information Engineering in 2007, from Al-Nahrain University. He is an associate professor since 2012 and head of the computer-engineering department. Dr Anas has published more than 12 published papers all of them in reputed journals and conferences

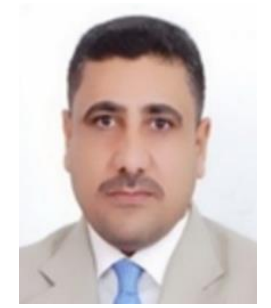

Mehdi J. Marie was born in Baghdad, Iraq in 1970. He received his Bachelor's (1993), Master's (2004) Degrees from University of Technology (Iraq) and Ph. D. from the University of Basrah (2014). He has been a lecturer of Control Theory I, II, Electronics and Electrical Networks at the AlNahrain University, College of Engineering. He is currently a senior engineer at Al-Zawaraa State Company, Ministry of Industry and Minerals (Iraq). Dr. Mehdi had achieved over seven Journal articles and two conference papers in the field of control and systems engineering. His current research and development interests aremainly in the following areas: self-tuning control and system identification, controllerdesign for linearand non-linear systems, industrial applications particularly in the processing industry (for example refining, cement, plastic and food industry).

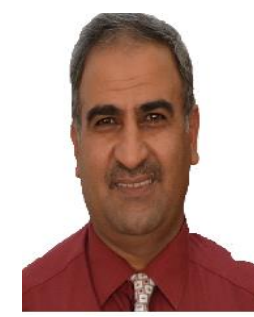

Khalaf S. Gaeid received the B.Sc. degree in electrical engineering/Control from MEC, Baghdad, Iraq in 1993 and the M.Sc. degree in Control Engineering from University of Technology, Baghdad, Iraq in 2004. He graduated from University of Malaya, Malaysia in 2012 with the PhD degree in control system and machine drives. His doctoral researchwas in the development new fault tolerant controller based wavelet for induction machines.He is currently assistant professor in control systems at the Department of Electrical Engineering, College of Engineering, Tikrit University, Tikrit, Iraq. His research interests include fault tolerant control, wavelet, fault diagnosis,machine drives and their applications in electrical engineering.He is IEEE member with a lot of publications in high rank journals and confrences 